This is the pre-peer reviewed version of the following article: Angew. Chem. Int. Ed. 2017, 56, $10755-10760$, which has been published in final form at https://onlinelibrary.wiley.com/doi/full/10.1002/anie.201704999. This article may be used for non-commercial purposes in accordance with Wiley Terms and Conditions for Use of Self-Archived Versions.

\title{
Semihydrogenation of Acetylene on Indium Oxide: Proposed Single-Ensemble Catalysis
}

\author{
Davide Albani ${ }^{+}$, Marçal Capdevila-Cortada ${ }^{+}$, Gianvito Vilé, Sharon Mitchell, Oliver Martin, \\ Núria López, * and Javier Pérez-Ramírez*
}

\begin{abstract}
Indium oxide catalyzes acetylene hydrogenation with high selectivity to ethylene (>85\%); even with a large excess of the alkene. In situ characterization reveals the formation of oxygen vacancies under reaction conditions, while an in depth theoretical analysis links the surface reduction with the creation of well-defined vacancies and surrounding $\mathrm{In}_{3} \mathrm{O}_{5}$ ensembles, which are considered responsible for this outstanding catalytic function. This behavior, which differs from that of other common reducible oxides, originates from the presence of four crystallographically inequivalent oxygen sites in the indium oxide surface. These resulting ensembles are 1) stable against deactivation, 2) homogeneously and densely distributed, and 3) spatially isolated and confined against transport; thereby broadening the scope of oxides in hydrogenation catalysis.
\end{abstract}

$\boldsymbol{H}$ eterogeneously catalyzed hydrogenations are widely applied in the production of numerous chemicals (for example, commodity, fine, specialty, and pharmaceutical chemicals). Intensive efforts have been devoted to reducing the ecological footprint of these processes, breaking away from the reliance on scarce noble metals $(\mathrm{Pd}, \mathrm{Pt}, \mathrm{Ru})$ and avoiding modification with toxic selectivity enhancers (for example, $\mathrm{Pb}, \mathrm{Bi}$, and $\mathrm{V}) .^{[1]}$ Two directions have shown significant promise: 1) targeting the improved design of noble-metal-based catalysts by reducing the size of the metal ensemble through development of ligand-modified systems, bimetallic compounds, and single-atoms heterogeneous catalysts, ${ }^{[1,2]}$ and 2) exploiting the untapped potential of metal oxides. ${ }^{[3]}$ In this context, cerium oxide and supported iron oxide have emerged as highly selective catalysts for the semihydrogenation of acetylene, a reaction integral to the purification of olefin streams for downstream polymerization processes. ${ }^{[3 \mathrm{~g}, 4]}$ Detailed mechanistic studies of the former have

[*] D. Albani, ${ }^{[+]}$Dr. G. Vilé, Dr. S. Mitchell, Dr. O. Martin,

Prof. J. Pérez-Ramírez

ETH Zurich, Department of Chemistry and Applied Biosciences

Institute for Chemical and Bioengineering

Vladimir-Prelog-Weg 1, 8093 Zurich (Switzerland)

E-mail:jpr@chem.ethz.ch

Dr. M. Capdevila-Cortada, ${ }^{[+]}$Prof. N. López

Institute of Chemical Research of Catalonia (ICIQ) and

The Barcelona Institute of Science and Technology

Av. Països Catalans 16, 43007 Tarragona (Spain)

E-mail:nlopez@iciq.es

$\left.{ }^{+}\right]$These authors contributed equally to this work.

(2) Supporting information and the ORCID identification number(s) for the author(s) of this article can be found under:

https://doi.org/10.1002/anie.201704999. unraveled the role of the surface $\mathrm{Ce}-\mathrm{O}$ pairs in activating molecular hydrogen $\left(\mathrm{H}_{2}\right)$ and stabilizing the various reaction intermediates. ${ }^{[4 a]}$ However, progressive surface reduction and oxygen $(\mathrm{O})$ vacancy formation induced rapid activity loss under operating conditions, limiting the performance of this oxide. ${ }^{[4 \mathrm{~b}, \mathrm{c}]}$ On the other hand, the fine dispersion of planar $\mathrm{Fe}^{\mathrm{II}, \mathrm{III}}$ oxide nanoparticles on appropriate acidic oxide supports required to attain a high chemo- and stereoselective character, still presents various synthetic challenges for the industrial implementation of this oxide. To date, no other metal oxides have been identified to selectively catalyze this reaction, leaving ample room for a more extensive investigation on the abilities of oxides in hydrogenation catalysis.

Indium oxide $\left(\operatorname{In}_{2} \mathrm{O}_{3}\right.$, bixbyite structure, space group $\left.I a \overline{3}\right)$ shows an intrinsic n-type conductivity related to the possibility of forming $\mathrm{O}$ vacancies and entrapping hydrogen atoms $(\mathrm{H})$, which act as carrier donors. ${ }^{[5]}$ We were intrigued by the rich electronic structure of $\operatorname{In}_{2} \mathrm{O}_{3}$, and by the promising catalytic properties recently identified in the synthesis of methanol from $\mathrm{CO}_{2}$ and $\mathrm{H}_{2} \cdot{ }^{[6]}$ Herein, the outstanding performance of $\mathrm{In}_{2} \mathrm{O}_{3}$ in the semihydrogenation of acetylene is described. In depth characterization reveals surface reduction by $\mathrm{O}$ vacancy formation, while detailed theoretical assessment points to the creation of a new type of active site comprising the $\mathrm{O}$ vacancy and surrounding $\operatorname{In}_{3} \mathrm{O}_{5}$ unit that behaves as a "single ensemble".

$\mathrm{In}_{2} \mathrm{O}_{3}$ was prepared by the controlled thermal decomposition of $\operatorname{In}(\mathrm{OH})_{3}$ at $673 \mathrm{~K}$ (see the Supporting Information for preparative details). Analysis by X-ray diffraction (XRD) confirms the transformation (Figure $1 \mathrm{a}$ ) of the hydroxide precursor to the pure oxide, as indicated by the sharp reflections of its XRD peaks, assigned to a compound with bixbyite structure with an estimated average crystal size of about $15 \mathrm{~nm}$. Examination by high-resolution transmission electron microscopy (HRTEM) reveals the presence of aggregated nanocrystals of comparable dimensions, which predominantly display the (111) facet (Figure 1 b; Supporting Information, Figure S2). The prevalence of this surface is in line with the lowest energy provided by first principles calculations. $^{[7 \mathrm{a}]}$ A type IV isotherm with type II hysteresis typical of a nanocrystalline material is observed by $\mathrm{N}_{2}$ sorption (Figure $\mathrm{S} 1$ ), evidencing a relatively high surface area $\left(108 \mathrm{~m}^{2} \mathrm{~g}^{-1}\right)$ and pore volume $\left(0.38 \mathrm{~cm}^{3} \mathrm{~g}^{-1}\right)$, and a discrete distribution of intercrystalline pore sizes centered on $10 \mathrm{~nm}$.

The performance of $\mathrm{In}_{2} \mathrm{O}_{3}$ was evaluated in the semihydrogenation of acetylene. Light-off curves, obtained by monitoring the acetylene conversion as the temperature was ramped from 523 to $673 \mathrm{~K}$, present a distinct S-shape, with the 


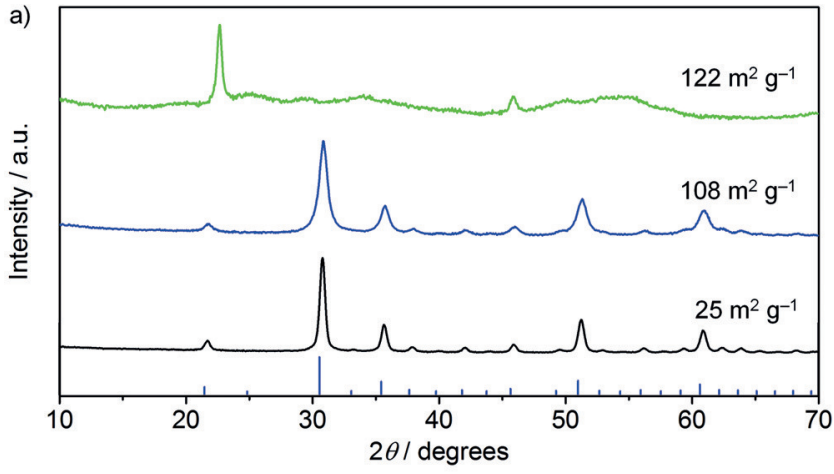

b)

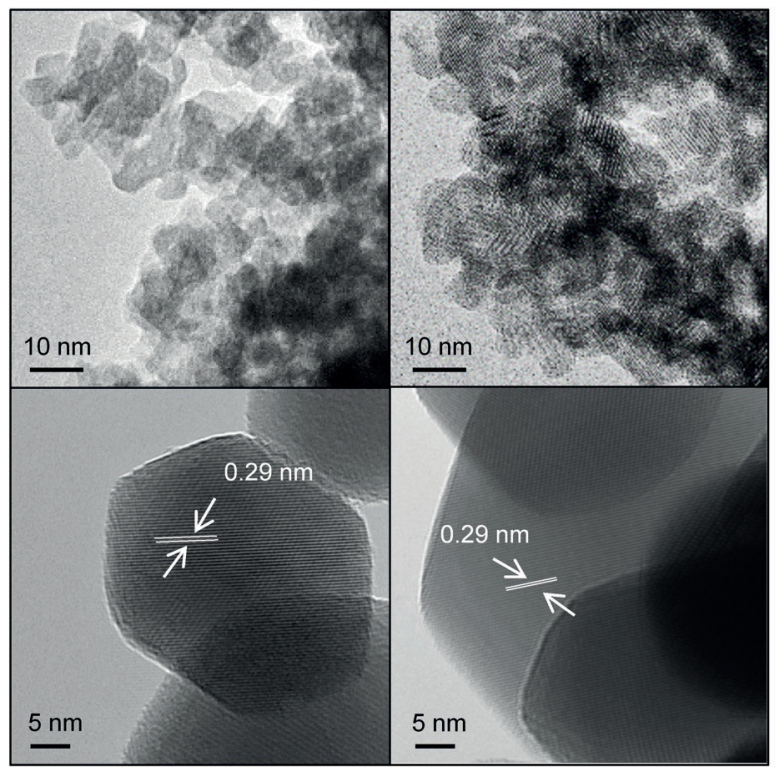

Figure 1. a) XRD patterns of $\ln (\mathrm{OH})_{3}(-), \ln _{2} \mathrm{O}_{3}(-)$, and $\ln _{2} \mathrm{O}_{3}$ after temperature cycle experiments at $523-673 \mathrm{~K}(-)$, and corresponding total surface area. b) Transmission electron micrographs of the $\ln (\mathrm{OH})_{3}$ precursor (top left), the fresh $\ln _{2} \mathrm{O}_{3}$ (top right), and the $\mathrm{In}_{2} \mathrm{O}_{3}$ after the temperature cycle experiments (bottom row). The vertical lines below the XRD patterns indicate the expected reflection positions of cubic $\ln _{2} \mathrm{O}_{3}$.

activity increasing abruptly from a few percent to full conversion by $600 \mathrm{~K}$. The selectivity toward $\mathrm{C}_{2} \mathrm{H}_{4}$ is around $95 \%$ in the low-conversion regime, and converges to about $85 \%$ at full conversion (Figure $2 \mathrm{a}$ ). Comparatively, fixing the temperature at $573 \mathrm{~K}$ and increasing the feed ratio of $\mathrm{H}_{2}: \mathrm{C}_{2} \mathrm{H}_{2}$ from 5 to 30 enhances the conversion (from 30 to $65 \%$ ) and selectivity to ethylene (from 38 to $85 \%$ ), while the selectivity to oligomers decreases (from 60 to $14 \%$, Figure 2b). Almost no overhydrogenated products (that is, $\mathrm{C}_{2} \mathrm{H}_{6}$ formation) are observed $(<5 \%)$ even at high feed ratios, which is a unique feature of oxides. ${ }^{[4]}$ No hysteresis in the activity is revealed upon cycling the temperature of the catalyst bed in the range $523-673 \mathrm{~K}$. A $100 \mathrm{~h}$ stability test conducted in the moderate conversion regime and applying excess ethylene in the feedconditions that would accelerate potential deactivation phenomena and selectivity issues-confirms the stable performance of $\mathrm{In}_{2} \mathrm{O}_{3}$ in acetylene semihydrogenation (Figure $2 \mathrm{c}$ ). The remarkable selectivity to ethylene was further demonstrated by a test at full conversion and in the presence of ethylene (Figure $2 \mathrm{~d}$ ).
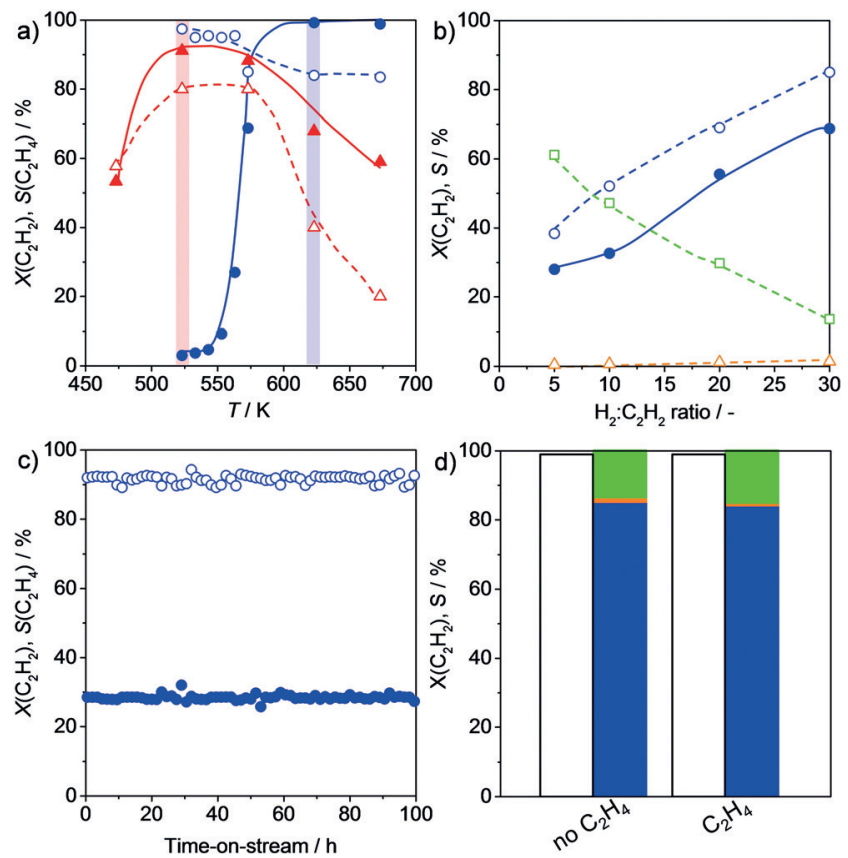

Figure 2. a) Acetylene conversion (solid symbol) and ethylene selectivity (open symbol) over $\ln _{2} \mathrm{O}_{3}$ (blue) and $\mathrm{CeO}_{2}$ (red) as a function of the reaction temperature at $\mathrm{H}_{2}: \mathrm{C}_{2} \mathrm{H}_{2}=30$. The temperature windows for the optimal performance of both catalysts are highlighted. b) Effect of the feed $\mathrm{H}_{2}: \mathrm{C}_{2} \mathrm{H}_{2}$ ratio on the acetylene conversion $(-\longrightarrow)$ and selectivity to ethylene (-----O----), ethane (---- $\triangle----)$, and oligomers (----- $\square----)$ over $\ln _{2} \mathrm{O}_{3}$ at $T=573 \mathrm{~K}$. c) Long-term test in the presence of excess ethylene at $T=558 \mathrm{~K}$; acetylene conversion ( $\bullet$ ) and selectivity to ethylene (○). d) Conversion ( $\square$ ) and selectivity to ethylene ( $\square$ ), ethane ( $\square$ ), and oligomers $(\square)$ in excess ethylene at $T=623 \mathrm{~K}$. Other conditions: $\tau=1 \mathrm{~s}, P=1$ bar.

Characterization of the catalyst by XRD after use in the cyclic experiments at $673 \mathrm{~K}$ demonstrates preservation of the $\mathrm{In}_{2} \mathrm{O}_{3}$ phase, which has an increased crystallinity (Figure 1). This agrees with the lower surface area of the used material $\left(25 \mathrm{~m}^{2} \mathrm{~g}^{-1}\right)$ with respect to the fresh catalyst, and the larger crystal size observed by microscopy analysis. Note that the crystals retain a similar morphology in the fresh and used catalysts, and the (111) surface remains dominant (Figures $1 \mathrm{~b}$ and S2). When performing the same cyclic measurement in Figure $2 \mathrm{a}$ over a wider temperature range (523-873 K), a drastic irreversible activity loss is observed above $850 \mathrm{~K}$ (Figure S3 a). The XRD pattern of the catalyst recovered after this test indicates complete reduction of the oxide to metallic In (Figure S3 b). To confirm the catalytic relevance of the (111) surface, $\mathrm{In}_{2} \mathrm{O}_{3}$ nanocubes mostly exposing (100) facets were synthesized and evaluated in acetylene semihydrogenation (Figure S4), exhibiting a rate of ethylene formation $\left(7.5 \mu \mathrm{mol}_{\mathrm{C}_{2} \mathrm{H}_{4}} \mathrm{~min}^{-1} \mathrm{~g}^{-1}\right)$ half that obtained over the original catalyst $\left(15.6 \mu \mathrm{mol}_{\mathrm{C}_{2} \mathrm{H}_{4}} \min ^{-1} \mathrm{~g}^{-1}\right)$. Analysis of the used catalyst confirmed the preservation of the cubic morphology under the testing conditions.

Compared to $\mathrm{In}_{2} \mathrm{O}_{3}, \mathrm{CeO}_{2}$ exhibits lower temperature activity (Figure $2 \mathrm{a}$ ), reaching a maximum acetylene conversion of $90 \%$ at $523 \mathrm{~K}$ with slightly inferior selectivity to ethylene $(80 \%)$. Progressive deactivation is observed at $T>575 \mathrm{~K}$, resulting from the formation of $\mathrm{O}$ vacancies 
under the reaction conditions. ${ }^{[4 b, c]}$ The distinct behavior of $\mathrm{In}_{2} \mathrm{O}_{3}$ and $\mathrm{CeO}_{2}$ is striking and calls for a more detailed mechanistic understanding of the performance of the former oxide in acetylene hydrogenation.

Hydrogenation reactions require the surface to efficiently activate $\mathrm{H}_{2}$. As shown by the temperature-programmed reduction $\left(\mathrm{H}_{2}\right.$-TPR) profile (Figure $\left.3 \mathrm{a}\right)$, the $\mathrm{In}_{2} \mathrm{O}_{3}$ catalyst displays a $\mathrm{H}_{2}$ uptake at about $500 \mathrm{~K}$, which is lower than the acetylene hydrogenation light-off temperature $(>550 \mathrm{~K}$, Figure $2 \mathrm{a}$ ). Temperature-programmed desorption of acetylene $\left(\mathrm{C}_{2} \mathrm{H}_{2}\right.$-TPD), on the other hand, shows that the interaction of $\mathrm{C}_{2} \mathrm{H}_{2}$ with $\mathrm{In}_{2} \mathrm{O}_{3}$ depends strongly on the temperature of adsorption. Upon adsorption at $523 \mathrm{~K}$, the $\mathrm{C}_{2} \mathrm{H}_{2}$-TPD profile exhibits a desorption peak centered at $643 \mathrm{~K}$. In contrast, only a weak signal at $355 \mathrm{~K}$ is observed after adsorption at $323 \mathrm{~K}$ (Figure S5). Density functional theory (DFT) calculations conducted on the stoichiometric $\operatorname{In}_{2} \mathrm{O}_{3}(111)$ surface reveal that $\mathrm{H}_{2}$ adsorption presents a large energy barrier $(0.85 \mathrm{eV})$, leading to two stable surface hydroxy groups $\left(E_{\mathrm{ads}}=-2.54 \mathrm{eV}\right.$ with respect to gas-phase $\mathrm{H}_{2}$, Figure $3 \mathrm{c}$ ). Comparatively, acetylene adsorption only requires an energy barrier of $0.46 \mathrm{eV}$ and results in an $\mathrm{In}-\mathrm{CHCH}-\mathrm{O}$ complex that exhibits strong chemisorption $(-1.51 \mathrm{eV}$ with respect to gas-phase acetylene). Hence, based on the energy values above, the adsorption of $\mathrm{H}_{2}$ on $\mathrm{In}_{2} \mathrm{O}_{3}$ is hampered in the presence of the alkyne. To validate this result, the catalyst was analyzed by $\mathrm{H}_{2}$-TPR after pretreatment with $\mathrm{C}_{2} \mathrm{H}_{2}$ at $523 \mathrm{~K}$ (Figure $3 \mathrm{a}$ ). Indeed, exposure of the catalyst to the alkyne induces a shift of the first reduction peak from 500 to $650 \mathrm{~K}$, confirming that $\mathrm{C}_{2} \mathrm{H}_{2}$ chemisorption prevents low-temperature surface reduction. Significantly, the $\mathrm{H}_{2}$ consumption peak starts exactly at $550 \mathrm{~K}$, which corresponds to the onset temperature of hydrogenation activity (Figure $2 \mathrm{a}$ ). In summary, once the temperature is ca. $535 \mathrm{~K}, \mathrm{C}_{2} \mathrm{H}_{2}$ starts desorbing from the surface. Molecular $\mathrm{H}_{2}$ can then adsorb dissociatively, generating two hydroxy species that can recombine to form water $\left(\mathrm{H}_{2} \mathrm{O}\right)$ with an activation energy of $1.20 \mathrm{eV}$. These steps have been experimentally verified by diffuse reflectance infrared Fourier transform spectroscopy (DRIFTS) under exposure to $\mathrm{H}_{2}$. This analysis clearly revealed the appearance of features indicative of $\mathrm{OH}$ bending at 1580, 1430, and $1370 \mathrm{~cm}^{-1}$, evidencing the formation of hydroxy species upon hydrogen activation (Figures $3 \mathrm{~b}$ and S6a). ${ }^{[7 b, c]}$ Upon reaching the onset temperature of surface reduction (Figure $3 \mathrm{a}$ ), broad bands assigned to $\mathrm{H}_{2} \mathrm{O}$ appear at 1680 and $1210 \mathrm{~cm}^{-1}$. The $\mathrm{H}_{2} \mathrm{O}$ formed only requires an additional $0.81 \mathrm{eV}$ for its desorption (see proceeding text), leaving behind a surface $\mathrm{O}$ vacancy (Figure 3c).

To address the state of the catalyst under reducing conditions, an ab initio thermodynamics analysis was carried out, taking into account the chemical potential of $\mathrm{H}$, In, and $\mathrm{H}_{2} \mathrm{O}$ (details are given in the Supporting Information). In the configurational pool, several surface motifs such as $\mathrm{O}$ vacancies, In adatoms, and $\mathrm{H}$ coverages were considered. The most relevant structures and the In adatom distribution are summarized in Figures S7 and S8, respectively. Under hydrogenation conditions (that is, atmospheric pressure and mild temperature), surface reduction is expected to occur by the loss of $\mathrm{H}_{2} \mathrm{O}$ and consequent vacancy formation (see
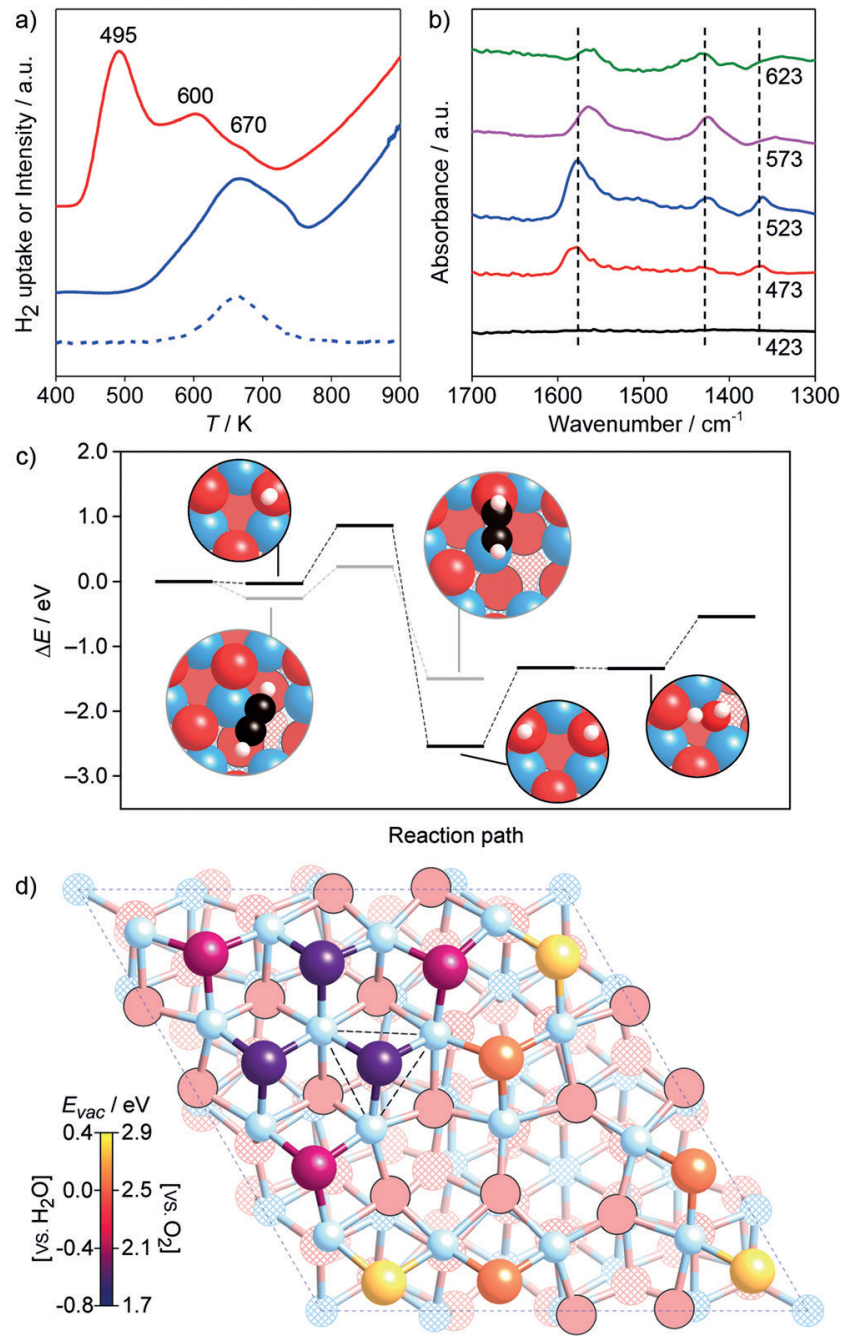

Figure 3. a) $\mathrm{H}_{2}$-TPR profiles of $\ln _{2} \mathrm{O}_{3}$, prior $(\longrightarrow)$ and after $(\longrightarrow)$ pretreatment with $\mathrm{C}_{2} \mathrm{H}_{2}$ at $523 \mathrm{~K}$, and $\mathrm{C}_{2} \mathrm{H}_{2}$-TPD on $\ln _{2} \mathrm{O}_{3}(-----)$. b) DRIFT spectra of $\mathrm{In}_{2} \mathrm{O}_{3}$ with varying temperature under $\mathrm{H}_{2}$ flow. c) Reaction profiles for the chemisorption of $\mathrm{C}_{2} \mathrm{H}_{2}(-)$ and the activation, with concomitant $\mathrm{H}_{2} \mathrm{O}$ formation, of $\mathrm{H}_{2}(-)$ on $\mathrm{In}_{2} \mathrm{O}_{3}(111)$. Inset: reaction intermediates; In (•), $\mathrm{O}(\bullet), \mathrm{C}(\bullet)$, and $\mathrm{H}$ $(\bigcirc)$; atoms at the surface (solid colors), atoms in the subsurface layer (hatched). d) Top view of the $\ln _{2} \mathrm{O}_{3}(111)$ surface where the 12 surface $\mathrm{O}$ atoms follow the color code according to their vacancy formation energy $\left(E_{\mathrm{vac}}\right)$ and the rest of the lattice is shown in light blue (In) and red $(\mathrm{O})$. The three In atoms belonging to the ensemble are connected with a black dashed triangle. The vacancy formation energies are calculated considering both $\mathrm{O}_{2}$ and $\mathrm{H}_{2} \mathrm{O}$ formation.

proceeding text). ${ }^{[\mathrm{a}, \mathrm{b}]}$ Nonetheless, In adatoms were also considered as potential active sites since they were identified to form in earlier scanning tunneling microscopy (STM) experiments upon annealing of $\operatorname{In}_{2} \mathrm{O}_{3}$ at $773 \mathrm{~K}$ in ultra-high vacuum (UHV). ${ }^{[8 c]}$ The dependence of the surface energy with respect to the $\mathrm{H}$ chemical potential, at fixed In and $\mathrm{H}_{2} \mathrm{O}$ chemical potentials $(-1.0$ and $-2.0 \mathrm{eV}$, respectively) is shown in Figure 4a (additional chemical potential scenarios are shown in Figure S9). From the results of Figures 4 a and S9, it is shown that In adatoms form at low $\mathrm{H}$ and high In chemical potentials; however, under the relevant hydrogenation con- 

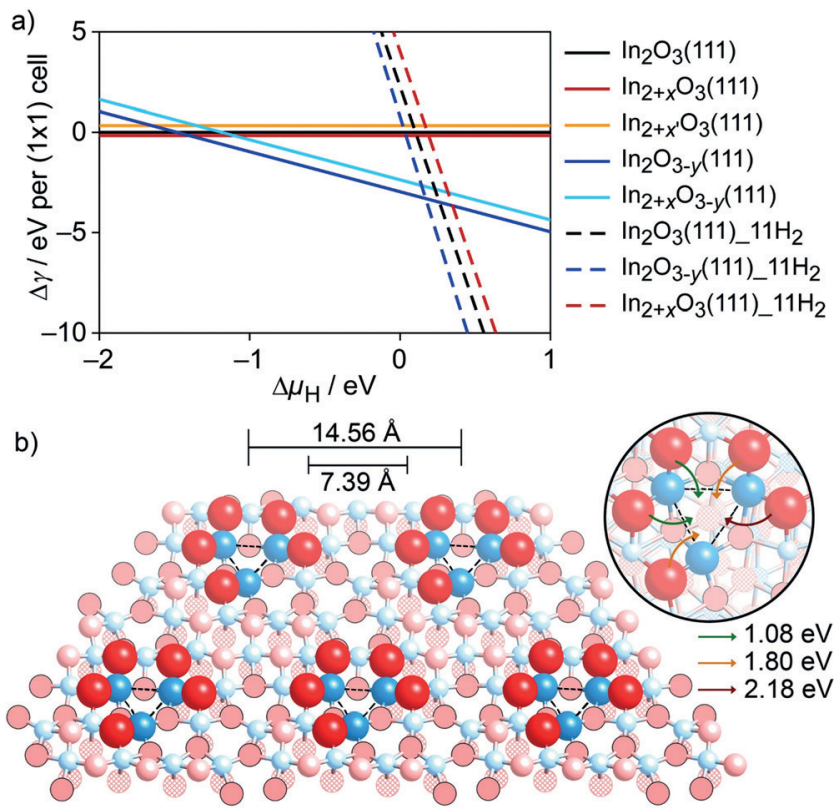

Figure 4. a) Relative surface energy per $(1 \times 1)$ cell of several reduced configurations, namely the partially reduced surfaces with one In adatom $\left(\ln _{2+x} \mathrm{O}_{3}(111)\right)$, one $\mathrm{O}$ vacancy $\left(\ln _{2} \mathrm{O}_{3-\gamma}(111)\right)$, two In adatoms $\left(\ln _{2+x} \mathrm{O}_{3}(111)\right)$, or one $\mathrm{In}$ adatom and one $\mathrm{O}$ vacancy $\left(\ln _{2+x} \mathrm{O}_{3-\gamma}(111)\right)$, and the stoichiometric surface $\left(\ln _{2} \mathrm{O}_{3}(111)\right)$, as a function of the hydrogen chemical potential. In $\left(\Delta \mu_{\mathrm{In}}\right)$ and $\mathrm{H}_{2} \mathrm{O}\left(\Delta \mu_{\mathrm{H}_{2} \mathrm{O}}\right)$ chemical potentials were fixed to -1.0 and $-2.0 \mathrm{eV}$, respectively. Completely hydrogenated surfaces were considered for $\ln _{2} \mathrm{O}_{3}(111)_{-} 11 \mathrm{H}_{2}$, $\ln _{2+x} \mathrm{O}_{3}(111)_{-} 11 \mathrm{H}_{2}$, and $\ln _{2} \mathrm{O}_{3-y}(111)_{-} 11 \mathrm{H}_{2}$. b) Single ensembles formed on $\mathrm{In}_{2} \mathrm{O}_{3}(111)$ under reaction conditions as a result of an $\mathrm{O}$ vacancy formation; In (๑) and $\mathrm{O}(\bullet)$ atoms. The three In atoms belonging to the ensemble are connected with a black dashed triangle. Diffusion channels of the surface $\mathrm{O}$ atoms adjacent to the vacancy are marked with arrows, the absence of outward diffusion paths indicates confinement of the vacancy.

ditions (for example, $p\left(\mathrm{H}_{2}\right) \approx 0.96$ bar), a single isolated $\mathrm{O}$ vacancy per unit cell is the most stable surface configuration. To further support the formation of vacancies, in situ Raman spectroscopy measurements in flowing $\mathrm{H}_{2}$ have been carried out, which reveal a reduction in the intensity of phonon scattering modes associated with $\mathrm{InO}_{6}$ octahedra (Figure S6b), in agreement with previous observations. ${ }^{[5 \mathrm{c}, 8 \mathrm{~d}]}$

These results corroborate that the surface state under reaction conditions is $\mathrm{O}$-depleted, and thus the nature and properties of the associated active site are further explored. Vacancy formation energies $\left(E_{\mathrm{vac}}\right)$ of the surface $\mathrm{O}$ atoms for the stoichiometric $\mathrm{In}_{2} \mathrm{O}_{3}(111)$ surface (Figure $3 \mathrm{~d}$ ) range between -0.64 and $0.30 \mathrm{eV}$ with respect to the gas-phase $\mathrm{H}_{2} \mathrm{O}$ reference. Differing from the lowest energy surface terminations of other representative oxides, four types of inequivalent atoms are distinguished (Table S1 and Figure S10). Those with the lowest abstraction energy are colored violet in Figure $3 \mathrm{~d}$. For this $\mathrm{O}$ vacancy, the excess charge delocalizes within the ensemble composed by the vacancy, the first neighboring In atoms, and the second neighboring $\mathrm{O}$ atoms (Figure S11). Once the first vacancy is formed, the abstraction of a second $\mathrm{O}$ at neighboring sites is less likely (Figure S12) whereas subsurface defects are also less stable (0.38 and $0.95 \mathrm{eV}$ for a vacancy in the higher and lower subsurface layers). Diffusion of the vacancy is only allowed through the three violet positions in Figure 3d, which lead to the formation of identical ensembles. Diffusion outside this confined region is not possible because of the high energy barriers (Figure 4b). As a result of the anisotropy of the lattice, in which $\mathrm{O}$ atoms are bonded to differently coordinated In atoms, the $\mathrm{O}$ vacancy is effectively shielded from aggregation and diffusion, which leads to its confinement and isolation.

The semihydrogenation of acetylene (Figure 5), and its potential overhydrogenation and oligomerization side paths, were investigated on the most stable surface configuration under reaction conditions (that is, a reduced $\mathrm{In}_{2} \mathrm{O}_{3-y}(111)$ surface). The adsorption of $\mathrm{C}_{2} \mathrm{H}_{2}$ occurs at an $\mathrm{In}-\mathrm{O}$ pair of the

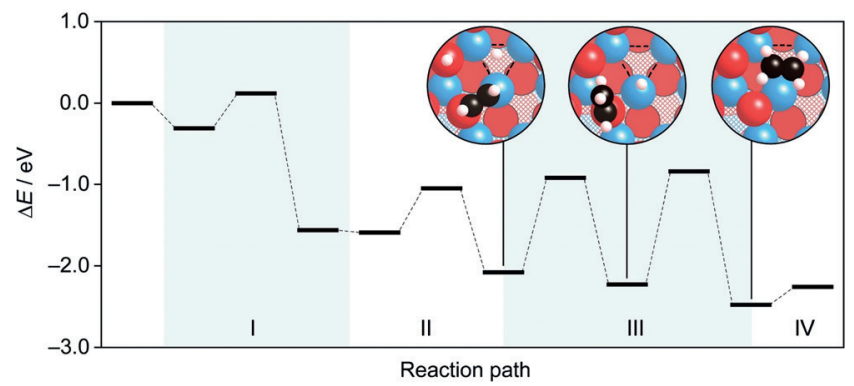

Figure 5. Energy profile for the semihydrogenation of acetylene on the reduced $\ln _{2} \mathrm{O}_{3-y}(111)$ surface, including $\mathrm{C}_{2} \mathrm{H}_{2}$ adsorption and activation (I), $\mathrm{H}_{2}$ coadsorption and activation (II), $\mathrm{C}_{2} \mathrm{H}_{2}$ hydrogenation (III), and $\mathrm{C}_{2} \mathrm{H}_{4}$ desorption (IV). Inset: reaction intermediates; color code as in Figure 3. The three In atoms belonging to the ensemble are connected with a black dashed triangle.

$\mathrm{In}_{3} \mathrm{O}_{5}$ ensemble adjacent to the vacancy, with strong bond polarization leading to $\mathrm{In}-\mathrm{C}^{\delta-} \mathrm{H}-\mathrm{C}^{\delta+} \mathrm{H}-\mathrm{O}$. In contrast to the stoichiometric surface, at the ensemble $\mathrm{H}_{2}$ is activated as $\mathrm{H}^{\delta-}-\mathrm{H}^{\delta+}$ in one of the neighboring $\mathrm{In}-\mathrm{O}$ pairs, where the $\mathrm{H}^{\delta-}$ moiety sits close to the vacant site. To prove that $\mathrm{C}_{2} \mathrm{H}_{2}$ and $\mathrm{H}_{2}$ compete for the same site, a kinetic analysis has been conducted, obtaining reaction orders of 0.5 for both reactants (Figures S13 a,b). Moreover the apparent activation energy of the reaction is about $80-90 \mathrm{~kJ} \mathrm{~mol}^{-1}$, which corresponds to the energy for $\mathrm{H}_{2}$ activation once the entropic and zero-point vibrational energies are taken into account (Figure S13c). The hydroxy proton can then be transferred to the adsorbed alkyne and the $\mathrm{H}^{\delta-}$ is subsequently transferred to the $\mathrm{O}-\mathrm{C}_{2} \mathrm{H}_{3}$ intermediate to form ethylene. The activation energies of both hydrogenation steps, 1.17 and $1.31 \mathrm{eV}$, respectively, are attainable at an experimental light-off temperature exceeding $550 \mathrm{~K}$.

The ethylene molecule formed, easily detaches from the ensemble because of its low desorption energy. The reaction intermediates of each hydrogenation step are shown in Figure S14, and the full reaction profile (combining the steps in Figures 3c and 5) is presented in Figure S15 of the Supporting Information. The overhydrogenation of the olefin is hindered as $\mathrm{C}_{2} \mathrm{H}_{4}$ desorption $(0.22 \mathrm{eV})$ requires significantly lower energy than its hydrogenation $(1.54 \mathrm{eV})$, in line with the 
low selectivity towards ethane $(<5 \%$, see preceding text). Similarly, the $\mathrm{C}-\mathrm{C}$ coupling of two coadsorbed $\mathrm{C}_{2} \mathrm{H}_{2}$ molecules presents rather low activation energy $(1.18 \mathrm{eV}$; Figure S16), explaining the high hydrogen partial pressure required to achieve the exceptional level of ethylene selectivity observed in Figure 2 b. Furthermore, to prove that the $\mathrm{In}_{3} \mathrm{O}_{5}$ ensemble is the sole active site, the reaction energy profile was also evaluated on the stoichiometric $\operatorname{In}_{2} \mathrm{O}_{3}(111)$ surface (Figure S17), showing that a high activation energy of $2.27 \mathrm{eV}$ is required for the second hydrogenation step. Similarly, the reaction cannot occur at the In adatom $\mathrm{In}_{2+x} \mathrm{O}_{3}(111)$ surface as the heterolytic activation of hydrogen is thermodynamically unfavorable (Figure S18) and the homolytic dissociation of $\mathrm{H}_{2}$ is very energy demanding (Figure S17). In summary, the complementary polarity of the $\mathrm{C}^{\delta-}-\mathrm{C}^{\delta+}$ and $\mathrm{H}^{\delta-}-\mathrm{H}^{\delta+}$ moieties found on the reduced $\mathrm{In}_{2} \mathrm{O}_{3-y}(111)$ surface facilitates the reaction and is responsible for the low activation energy of both hydrogenation steps. As the heterolytic activation of $\mathrm{H}_{2}$ is only possible at the ensemble created upon vacancy formation (Figure S18), this represents the only site where the reaction can proceed with low energy requirement.

In conclusion, we have described $\operatorname{In}_{2} \mathrm{O}_{3}$ as a novel catalyst for the semihydrogenation of acetylene, which exhibits $85 \%$ ethylene selectivity at full conversion even in ethylene excess and at temperatures above $550 \mathrm{~K}$. Theoretical models rationalize this outstanding performance predicting the formation, under reaction conditions, of a unique $\mathrm{In}_{3} \mathrm{O}_{5}$ site consisting of an $\mathrm{O}$ vacancy, an In trimer, and adjacent $\mathrm{O}$ atoms, where $\mathrm{C}_{2} \mathrm{H}_{2}$ and $\mathrm{H}_{2}$ can coadsorb and react. The precisely defined nature of these ensembles, which represent a novel variant of ensemble size control for non-metallic systems in hydrogenations, originates from the low symmetry of the $\operatorname{In}_{2} \mathrm{O}_{3}$, which permits a high ensemble density (ca. 0.08 ML) while ensuring isolation (as diffusion is hindered) and avoiding lateral interactions with other centers. Since the active center contains different types of atoms, this site is denoted as a "single-ensemble heterogeneous catalyst" (SEHC). In contrast to oxidation reactions where vacancy sites are considered active centers, this SEHC requires both the In and $\mathrm{O}$ atoms surrounding the empty site for the reaction to occur. When compared to single-atom heterogeneous catalysts (SAHC), on the other hand, where atomic dispersion and high densities are very difficult to attain simultaneously, the confinement and robustness of the ensemble circumvent typical pitfalls related to the miniaturization of the ensemble. Oxides presenting large unit cells with marked anisotropy are natural scaffolds for single-ensemble sites representing new selective catalytic materials for hydrogenations and beyond. Future advances in microscopy techniques will be essential to gain a deeper understanding of these sites.

\section{Acknowledgements}

Financial support from ETH Zurich, ICIQ Foundation, the Spanish MINECO (CTQ2015-68770-R), and the Swiss National Science Foundation (Grant No. 200021-169679) is acknowledged. ScopeM at ETH Zurich is thanked for providing access to its facilities. O. Sambalova and Dr. A. Borgschulte (EMPA Dübendorf) are thanked for the in situ Raman experiments. M.C.-C. also acknowledges MINECO for a "Juan de la Cierva-Formación" fellowship (FJCI-201420568). We would like to thank U. Diebold and M. Wagner (TU Wien) for discussions.

\section{Conflict of interest}

The authors declare no conflict of interest.

Keywords: alkyne semihydrogenation . density functional theory · ensembles · indium oxide . site isolation

[1] a) M. Sankar, N. Dimitratos, P. J. Miedziak, P. P. Wells, C. J. Kiely, G. J. Hutchings, Chem. Soc. Rev. 2012, 41, 8099-8139; b) G. Vilé, D. Albani, N. Almora-Barrios, N. López, J. Pérez-Ramírez, ChemCatChem 2016, 8, 21-33.

[2] a) F.-M. McKenna, J. A. Anderson, J. Catal. 2011, 281, 231-240; b) A. J. McCue, A. Guerrero-Ruiz, I. Rodrígez-Ramos, J. A. Anderson, J. Catal. 2016, 340, 10-16; c) Y. Luo, S. A. Villaseca, M. Friedrich, D. Teschner, A. Knop-Gericke, M. Armbrüster, $J$. Catal. 2016, 338, 265-272; d) G. Kyriakou, M. B. Boucher, A. D. Jewell, E. A. Lewis, T. J. Lawton, A. E. Baber, H. L. Tierney, M. Flytzani-Stephanopoulos, E. C. H. Sykes, Science 2012, 335, 1209-1212; e) F. R. Lucci，J. Liu， M. D. Marcinkowski， M. Yang, L. F. Allard, M. Flytzani-Stephanopoulos, E. C. H. Sykes, Nat. Commun. 2015, 6, 8550; f) H. Wei, X. Liu, A. Wang, L. Zhang, B. Qiao, X. Yang, Y. Huang, S. Miao, J. Liu, T. Zhang, Nat. Commun. 2014, 5, 5634; g) G. Xu, H. Wei, Y. Ren, J. Yin, A. Wang, T. Zhang, Green Chem. 2016, 18, 1332-1338; h) P. Liu, Y. Zhao, R. Qin, S. Mo, G. Chen, L. Gu, D. M. Chevrier, P. Zhang, Q. Guo, D. Zang, B. Wu, G. Fu, N. Zheng, Science 2016, 352, $797-$ 800 ; i) G. Vilé, D. Albani, M. Nachtegaal, Z. Chen, D. Dontsova, M. Antonietti, N. López, J. Pérez-Ramírez, Angew. Chem. Int. Ed. 2015, 54, 11265-11269; Angew. Chem. 2015, 127, 11417-11422.

[3] a) E. J. Grootendorst, R. Pestman, R. M. Koster, V. Ponec, J. Catal. 1994, 148, 261-269; b) Y. Sakata, V. Ponec, Appl. Catal. A 1998, 166, 173-184; c) R. V. Jagadeesh, A.-E. Surkus, H. Junge, M.-M. Pohl, J. Radnik, J. Rabeah, H. Huan, V. Schünemann, A. Brückner, M. Beller, Science 2013, 342, 1073-1076; d) A. Primo, F. Neatu, M. Florea, V. Parvulescu, H. Garcia, Nat. Commun. 2014, 5, 5291; e) K. V. Kovtunov, D. A. Barskiy, O. G. Salnikov, A. K. Khudorozhkov, V. I. Bukhtiyarov, I. P. Prosvirin, I. V. Koptyug, Chem. Commun. 2014, 50, 875-878; f) J. Song, Z.-F. Huang, L. Pan, J. Zou, X. Zhang, L. Wang, ACS Catal. 2015, 5, 6594-6599; g) M. Tejada-Serrano, J. R. Cabrero-Antonino, V. Mainar-Ruiz, M. López-Haro, J. C. Hernández-Garrido, J. J. Calvino, A. Leyva-Pérez, A. Corma, ACS Catal. 2017, 7, $3721-$ 3729.

[4] a) G. Vilé, B. Bridier, J. Wichert, J. Pérez-Ramírez, Angew. Chem. Int. Ed. 2012, 51, 8620-8623; Angew. Chem. 2012, 124, $8748-$ 8751; b) G. Vilé, S. Wrabetz, L. Floryan, M. E. Schuster, F. Girgsdies, D. Teschner, J. Pérez-Ramírez, ChemCatChem 2014, 6, 1928-1934; c) G. Vilé, S. Colussi, F. Krumeich, A. Trovarelli, J. Pérez-Ramírez, Angew. Chem. Int. Ed. 2014, 53, 12069-12072; Angew. Chem. 2014, 126, $12265-12268$.

[5] a) T. Koida, H. Fujiwara, M. Kondo, Jpn. J. Appl. Phys. 2007, 46, L685-L687; b) S. Limpijumnong, P. Reunchan, A. Janotti, C. Van de Walle, Phys. Rev. B 2009, 80, 193202; c) T. Bielz, H. 
Lorenz, W. Jochum, R. Kaindl, F. Klauser, B. Klötzer, S. Penner, $J$. Phys. Chem. C 2010, 114, 9022-9029; d) W. Yin, K. Smithe, P. Weiser, M. Stavola, W. B. Fowler, L. Boatner, S. J. Pearton, D. C. Hays, S. G. Koch, Phys. Rev. B 2015, 91, 075208; e) A. Walsh, Appl. Phys. Lett. 2011, 98, 261910.

[6] O. Martin, A. J. Martín, C. Mondelli, S. Mitchell, T. F. Segawa, R. Hauert, C. Drouilly, D. Curulla-Ferré, J. Pérez-Ramírez, Angew. Chem. Int. Ed. 2016, 55, 6261-6265; Angew. Chem. 2016, 128, $6369-6373$.

[7] a) A. Walsh, R. A. Catlow, J. Mater. Chem. 2010, 20, 10438 10444; b) M. Jothibas, C. Manoharan, S. S. Jeyakumar, P. Praveen, J. Mater. Sci. Mater. Electron. 2015, 26, 9600-9606; c) G. M. Silva, E. H. de Faria, E. J. Nassar, K. J. Ciuffi, P. S. Calefi, Quim. Nova 2012, 35, 473-476.
[8] a) K. H. L. Zhang, R. G. Egdell, F. Offi, S. Iacobucci, L. Petaccia, S. Gorovikov, P. D. C. King, Phys. Rev. Lett. 2013, 110, 056803; b) F. Lei, Y. Sun, K. Liu, S. Gao, L. Liang, B. Pan, Y. Xie, J. Am. Chem. Soc. 2014, 136, 6826-6829; c) M. Wagner, S. Seiler, B. Meyer, L. A. Boatner, M. Schmid, U. Diebold, Adv. Mater. Interfaces 2014, 1, 1400289; d) M. Kumar, V. N. Singh, F. Singh, K. V. Lakshmi, B. R. Mehta, J. P. Singh, Appl. Phys. Lett. 2008, 92, 171907. 